Review

\title{
Unfolded Protein Responses With or Without Unfolded Proteins?
}

\section{Erik L. Snapp}

Department of Anatomy and Structural Biology, Albert Einstein College of Medicine, 1300 Morris Park Avenue, Bronx, NY 10461, USA; E-Mail: erik-lee.snapp@einstein.yu.edu; Tel.: +718-430-2967; Fax: +718-430-8996

Received: 17 September 2012; in revised form: 15 October 2012 / Accepted: 22 October 2012 / Published: 1 November 2012

\begin{abstract}
The endoplasmic reticulum (ER) is the site of secretory protein biogenesis. The ER quality control (QC) machinery, including chaperones, ensures the correct folding of secretory proteins. Mutant proteins and environmental stresses can overwhelm the available QC machinery. To prevent and resolve accumulation of misfolded secretory proteins in the ER, cells have evolved integral membrane sensors that orchestrate the Unfolded Protein Response (UPR). The sensors, Ire1p in yeast and IRE1, ATF6, and PERK in metazoans, bind the luminal ER chaperone BiP during homeostasis. As unfolded secretory proteins accumulate in the ER lumen, BiP releases, and the sensors activate. The mechanisms of activation and attenuation of the UPR sensors have exhibited unexpected complexity. A growing body of data supports a model in which Irelp, and potentially IRE1, directly bind unfolded proteins as part of the activation process. However, evidence for an unfolded protein-independent mechanism has recently emerged, suggesting that UPR can be activated by multiple modes. Importantly, dysregulation of the UPR has been linked to human diseases including Type II diabetes, heart disease, and cancer. The existence of alternative regulatory pathways for UPR sensors raises the exciting possibility for the development of new classes of therapeutics for these medically important proteins.
\end{abstract}

Keywords: unfolded protein response; endoplasmic reticulum; misfolded protein; BIP; stress; Ire 1; inositol

\section{Introduction}

Nascent secretory proteins enter the endoplasmic reticulum (ER) lumen and immediately encounter a myriad of quality control (QC) effectors that enhance correct protein folding and prevent and resolve 
accumulation of misfolded secretory proteins in the ER [1,2]. The QC effectors include chaperones, folding enzymes, and ER-associated degradation (ERAD) retrotranslocation machinery [3]. The effectors are constitutively expressed, but can be dramatically upregulated by the integral membrane sensors that mediate the Unfolded Protein Response (UPR) [4]. The sensors include Ire1p (in the yeast S. cerevisiae [5]) and IRE1 $\alpha$ (highly homologous to the yeast Ire1p), PERK, and ATF6) [6-9] in metazoans. Each UPR stress sensor has a discrete set of downstream targets that help a cell resolve an unfolded protein burden $[3,4,10,11]$. PERK transiently attenuates global protein translation to decrease the nascent protein burden [12]. In addition, ER volume expands to help dilute any accumulation of unfolded proteins in the ER [13]. All of the sensors are integral membrane proteins. Upon unfolded protein accumulation, the sensors activate by either oligomerizing or, in the case of ATF6, exit the ER through vesicular trafficking to the Golgi complex for proteolytic processing. PERK and IRE1 $\alpha /$ Ire $1 p$ each form homo-oligomers and stimulate their effectors, i.e., HAC1 mRNA splicing for Irelp (Figure 1) [6,14]. PERK phosphorylates eIF2 $\alpha$ to attenuate general translation [12]. IRE1 $\alpha$ cleaves $X B P 1$ (Ire1p similarly cleaves $H A C 1$ ) mRNA and a tRNA ligase splices the transcription factor in frame, enabling the correctly spliced form to upregulate chaperones and ERAD components [6,15]. ATF6 is proteolytically cleaved, releasing a transcription factor [6,16]. Similar to Xbp1 and Hac1p, the ATF6 transcription factor upregulates ER QC machinery [17]. If the metazoan UPR fails to resolve the stress, caspases can be activated leading to cell death [18]. For this reason, UPR resolution is considered critical for a cell survival. Curiously, in yeast, which lacks a metazoan apoptotic pathway, it also appears to be critical to keep the UPR below a certain threshold for survival [19,20]. As several human diseases have been linked to insufficient or excessive UPR [21-23], understanding the fundamental mechanisms of the UPR is a medically important goal. While much is known concerning the biology of the effectors, the activation and attenuation of the UPR sensors remain less well understood. In the following review, we will focus on the prototypical ER stress sensor, Ire1p and its human homolog IRE1 $\alpha$ and recent progress on these problems.

Figure 1. Illustration of Ire1p activation and inactivation. Unfolded protein accumulation and inositol depletion stimulate $\mathrm{BiP} / \mathrm{Kar} 2 \mathrm{p}$ release and Ire1p oligomerization. Splicing of HAC1 mRNA is further enhanced by peptide binding to Irelp and Ire $1 p$ clustering. Increased levels of Haclp upregulate UPR effectors leading to resolution of stress.

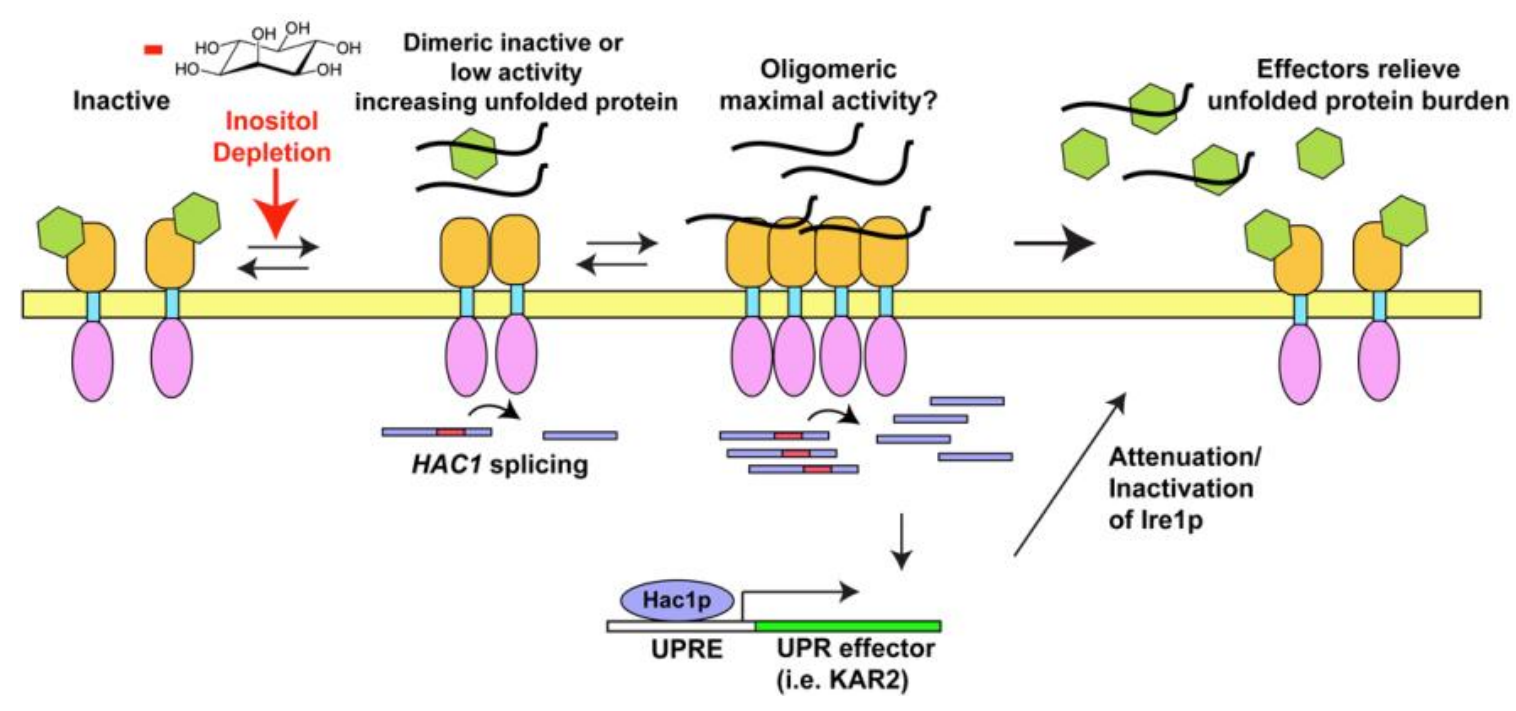




\section{Conceptual Model for Sensing Stress}

Before analyzing the specific case of Ire1p/IRE1 $\alpha$ regulation, I'd like to briefly consider the general problem of sensing and resolving stressful conditions. Cells have evolved several different strategies for detecting and responding to environmental conditions that perturb homeostasis, thus causing forms of "stress". There are two fundamental steps for stress pathways: (1) Detection of the stressful condition and (2) activation of a cellular protein or network of proteins to enact a program that enables the cell to adapt and/or restore homeostasis. The potential solutions for these requirements are numerous. A stressful substrate could inhibit, activate or alter the stability of sensor or effector proteins. Once activated, the sensor or effector could undergo further regulation by covalent posttranslational modifications, such as phosphorylation

In simple cases, a stressor is a unique metabolite that directly binds a sensor. However, many stresses are broadly acting physico-chemical changes, i.e., heat, osmotic or oxidative damage, that impact a broad array of targets. The sensing of misfolded protein accumulation falls into this more challenging category, in that proteins can misfold in numerous ways and few proteins share conserved sequences. Cellular chaperone proteins generally can recognize a diverse variety of incompletely folded or misfolded proteins often through exposure of hydrophobic domains that are usually buried in a properly folded protein [24]. Chaperones assist in protein folding and prevent protein aggregation. Thus, a chaperone or a chaperone domain would be a logical solution for sensing a misfolded protein accumulation.

One of the earliest misfolded protein stress pathways is the bacterial heat shock response that involves a transcription factor, $\sigma 32$, that is negatively regulated by the bacterial Hsp70, DnaK [25]. $\sigma 32$ has a short half-life and can be inactivated by binding to DnaK. Upon stress, unfolded protein levels overwhelm DnaK, titrating available pools of DnaK from $\sigma 32$, leading to increased levels and stability of $\sigma 32$, which, in turn, stimulates transcription of DnaK and other chaperones whose genes have $\sigma 32$ elements in their promoters [25]. In eukaryotes, a similar strategy is employed for the Heat Shock Response. The cytoplasmic Hsp90 ATPase chaperone binds the Heat Shock Factor 1 (HSF1) transcription factor [26]. During nonstressful conditions, a small fraction of the highly expressed pool of Hsp90 molecules binds HSF1 and retains the protein in the cytoplasm. Stresses that increase levels of misfolded cytoplasmic proteins increase occupancy of the main pool of Hsp90 with clients. Liberation of Hsp90 permits HSF1 to trimerize, enter the nucleus, and increase transcription of HSP70, HSP90, and other chaperones and effectors to resolve the misfolded protein stress [26]. Attenuation of the Heat Shock Response is not well understood, but requires inactivation of HSF1, which appears to involve acetylation of HSF1 [26].

In the ER, the secretory protein folding environment also contains several chaperones and must be protected from accumulating misfolded proteins. However, sensing of accumulating misfolded secretory proteins must be transmitted across a membrane barrier. One solution for the sensing problem would be to evolve a protein that detects misfolded proteins and one or more transmembrane proteins to convey the signal across the ER membrane. The sensor and effector could even be part of a single integral membrane protein sensor/effector molecule. Once activated, the response could be attenuated by either degrading the sensor protein, post-translational modifications to the sensor and/or some obstruction of the ability to interact with effector molecules. The integral ER membrane protein, 
Ire1p in yeast and IRE1 $\alpha$ in mammalian cells, satisfies at least some of these criteria and is essential for regulating the mRNA for the key UPR effector, $H A C l$ in yeast and Xbpl in metazoans [4].

\section{Ire1p and IRE1 $\alpha$ Structure and Function}

The yeast enzyme Ire1p was first identified in a screen for inositol auxotrophs, leading to the name Inositol Requiring Enzyme (Ire1p) [27]. IRE1 was essential for yeast to grow on synthetic media lacking inositol. The following year, the team of Kazu Mori and Mary-Jane Gething and the team of Peter Walter and Jeff Cox both reported that yeast lacking IRE1 could not grow on stressors that induced the accumulation of misfolded secretory proteins, including the compounds tunicamycin (Tm) and DTT, which prevented N-linked glycosylation of N-X-S/T consensus peptides or disrupted disulfide bond formation, respectively [28,29]. The metazoan UPR is sensitive to the sarco/endoplasmic reticulum $\mathrm{Ca}^{2+}$ ATPase (SERCA) calcium channel inhibitor thapsigargin (Tg), which depletes the ER of calcium [30]. Potential clues to the mechanism of Irelp function came from the recognition that the Irelp cytoplasmic domain contained significant homology to the mammalian ribonuclease RNase L [31] and the observation that the mRNA of the genetically linked transcription factor, Haclp, was spliced during ER stress only in cells that expressed IRE1 [29], though splicing did not significantly increase Hac1p stability [47]. Irelp performs the specific cytoplasmic RNA cleavage event, while a tRNA ligase completes the splicing reaction [32]. The metazoan IRE1 similarly cleaves the $X b p 1$ transcription factor mRNA [33].

\subsection{Irelp/IRE1 $\alpha$ Structure}

Ire1p and IRE1 $\alpha$ are single pass Type I integral membrane proteins [27]. The yeast protein has four potential N-linked glycosylation sites while the human form has one. Both proteins have three luminal cysteines. Neither the N-linked glycosylation sites nor the cysteines appear to influence Irelp activity [34]. Kenji Kohno's lab has extensively mutagenized Ire1p and characterized five functionally distinct subdomains of the $\mathrm{NH}_{2}$-terminal luminal domain [35]. In particular, Domains II-IV were defined as the "core stress-sensing" domains, with Domain IV being especially important for dimerization of the luminal domain during stress and Ire1p activation [34]. Domain V was identified as the Kar2p binding domain [35] (the ER Hsp70, BiP in mammalian cells, see Section 5. Domains II and IV, when dimerized, form a structure capable of binding unfolded peptides [36-38]. On the cytoplasmic side, the $\mathrm{COOH}$-terminal domain contains a kinase domain and an RNase domain [27-29]. The RNase domain performs at least three effector roles including: $H A C 1 / X b p 1$ mRNA cleavage, degradation of ER membrane associated mRNAs (termed Regulated Ire1-Dependent Decay (RIDD)), and 28S ribosomal cleavage [33,39-43]. Metazoan IRE1 has been frequently considered a pro-survival arm of the UPR $[44,45]$. However, the overexpressed form of IRE1 $\alpha$ used to arrive at this conclusion was kinase dead and not capable of the pro-apoptotic RIDD activity in wt IRE1 $\alpha$ [42]. Thus, at different stages in the stress response, IRE $1 \alpha$ can be either protective or pro-death. While many of the mechanistic details of Ire1p/IRE1 $\alpha$ structure-function have been determined, the initial steps of activation and the mechanism of attenuation of Ire $1 \mathrm{p} / \mathrm{IRE} 1 \alpha$ remain enigmatic. 


\subsection{Ire1p Functional Assays}

Ire1p undergoes changes in oligomerization, phosphorylation, clustering, and HAC1 RNA splicing activity. The spliced $H A C l$ output can be measured by multiple assays including Northern blot of spliced mRNA, RT PCR of spliced and unspliced mRNA, fluorescent signal from the product of an out of translational reading frame fluorescent protein mRNA that Ire1p splices into frame, changes in transcript levels of a Haclp transcription factor targeted gene (i.e., INO1 or KAR2), measurement of fluorescence or $\beta$-galactosidase activity produced by a transcriptional reporter containing a UPR response element promoter upstream of a fluorescent protein or LacZ reporter, assays of Ire1p clustering (FRET, live cell fluorescence imaging, and immunofluorescence) and growth of yeast on plates under stressful conditions. As astutely noted in Credle et al. [38], the choice of assay can have very different outcomes, as the outputs will depend on the stability of the product and whether amplification of the product occurs during the assay. For example, a single transcription factor could theoretically produce many transcripts, which in turn could produce multiple proteins from each transcript - a significant amplification of signal. Similarly, fluorescent proteins tend to be highly stable, where as spliced HACl mRNA has a short half-life $(\sim 20 \mathrm{~min})$ [46] and Haclp has a half-life of two min [47,48]. Measurement of spliced $H A C l$ levels is one of the few assays that permit detection of inactivation of Ire1p following stress resolution. Pincus et al. cleverly found that changes in the rate of GFP synthesis could serve as a comparable surrogate measure [49]. Several of the assays report features increasingly removed from the specific actions of Ire1p. For example, spliced HAC1 levels are a combined measure of amount of spliced mRNA and mRNA stability. Importantly, unspliced $H A C l$ is relatively stable, which will affect ratiometric quantitation [50]. In light of these caveats, comparisons of Ire $1 p$ activity suggest that minor differences in Ire $1 p$ splicing activity can result in dramatic differences in downstream UPR activity. When considering the effects of various mutations on Ire1p function, the choice of assay and timing of the readout can impact interpretation of the consequences of the mutation.

\section{Ire1p/IRE1 $\alpha$ Activation Models}

What are the mechanistic steps required for Irelp/IRE1 $\alpha$ activation? A wide range of stimulipharmacologic, mutant misfolded proteins, and manipulations that alter luminal ER chaperone availability for nascent proteins- have been correlated with an Unfolded Protein Response [11] and specifically with Ire1p/IRE1 $\alpha$ activation [51]. Ire1p activation includes oligomerization and phosphorylation [14,52] and correlates temporally at very early times with the accumulation of unfolded secretory proteins. Similarly, increasing occupancy of the ER Hsp70 chaperone BiP with unfolded secretory protein clients is coincident with the earliest downstream events of $X b p 1$ splicing [53]. Misfolded secretory protein levels could be sensed by Ire1p/IRE1 $\alpha$ (1) directly by Ire1p/IRE1 $\alpha$, (2) through Ire1p/IRE1 $\alpha$ regulation by BiP, and/or (3) by additional proteins.

\subsection{Density Dependent Activation of Ire1p}

Different studies suggest Ire1p/IRE $\alpha$ needs to be restrained from activating. Overexpression of IRE $1 \alpha /$ Ire1p activates constitutive $X b p 1 / H A C 1$ splicing, though not as robustly as a Tm stress [52,54]. 
Constitutive overexpression of IRE1 $\alpha$ is not tolerated by mammalian cells, presumably due to the apoptotic consequences of RIDD [42]. In the absence of regulatory factors, the purified Ire1p cytoplasmic domain dimerizes in vitro independent of the luminal domain [55,56] or phosphorylation $[20,55]$, but appears to require binding to ADP [20]. The purified luminal domain also readily dimerizes [36,57]. Thus, as concentrations of Ire $1 \mathrm{p} / \mathrm{IRE} 1 \alpha$ increase, the proteins become increasingly prone to collisions, leading to oligomerization, a requirement for activation. These findings suggest that Ire $1 \mathrm{p} / \mathrm{IRE} 1 \alpha$ could be activated simply by density dependent collisions or that overexpression in cells could titrate an inhibitory factor. Increased levels of Ire $1 \mathrm{p} / \mathrm{IRE} 1 \alpha$ could also increase the probability of encountering a hypothetical activating factor. There is no evidence that Ire1p/IRE1 $\alpha$ expression levels change significantly prior to or during UPR activation. In fact, Ire1 $p$ is normally expressed at exceptionally low levels in most cell types. Given the propensity of purified Ire1p domains to oligomerize in vitro, the need for one or more inhibitory molecules to regulate Ire $1 p$ is logical.

\subsection{Irelp Sensing of Unfolded Proteins}

Ire1p/IRE1 $\alpha$ oligomerizes as unfolded secretory proteins accumulate in the ER [14,52]. Oligomerization is essential for Ire1p/IRE1 $\alpha$ function $[38,58,59]$. Monomeric Ire1p does not undergo phosphorylation or perform $H A C 1$ splicing [58]. Oligomerization is a prerequisite for phosphorylation [52]. Crystal structures have been solved for both the luminal $[38,60]$ and cytoplasmic domains [56,61-63] of Ire1p and IRE1 $\alpha$. Interestingly, the purified domains crystallize as a pair of twisting strands. Each strand is assembled from oligomers of repeating dimers. The monomers bind each other at two distinct interfaces to enable formation of higher order oligomers [38,56]. Whether the oligomers that form in cells are highly ordered Ire1p/IRE1 $\alpha$ complexes is unclear. Nor is it obvious how many copies of Ire1p/IRE1 $\alpha$ are in cellular oligomers or what the functional minimal oligomer is. However, evidence from Kimata et al., Li et al. and Aragón et al. reveals that Irelp and IRE1 $\alpha$ both cluster in the ER membrane during stress [37,54,58]. Transmission electron micrographs suggest the clusters even cause localized distortions in the ER membrane [37]. Studies of mutagenized dimerization interfaces of Irelp found higher order clustering was required for maximal activation and Ire1p splicing activity [36,37,58].

The UPR can be activated to differing degrees over a large range of compound concentrations [10,49]. Even outputs (upregulated genes) can differ for stresses that quantifiably activate Ire1p to comparable levels [64]. Thus, the UPR is not an all or nothing system. Ire1p/IRE1 $\alpha$ appears to be able to detect differences between stresses and respond proportionately. This might happen through modulation of a negative regulatory factor or even through direct detection of changes in unfolded secretory protein levels.

A growing body of data support direct detection of unfolded secretory proteins by Ire1p $[36,37,65]$. On the basis of the structural similarity of the Ire1p to the peptide-binding groove of MHC-1, Peter Walter proposed the peptide-binding hypothesis. In this model, Ire1p directly senses the accumulation of unfolded secretory proteins in the ER lumen by binding the peptides to the MHC-1-like domain. The Ire1p luminal domain (Subdomains II-IV) (Figure 2), upon dimerization, can demonstrably bind unfolded protein domains [36-38]. Mutagenesis of key residues in the major histocompatibility complex 1 (MHC1)-like peptide binding cleft decreases Ire1p mutant activation during misfolded 
secretory protein accumulation [36,38]. The ability of Irelp to bind unfolded proteins correlates reasonably well with the ability to acutely stimulate Ire $1 p$ phosphorylation and $H A C 1$ splicing activity. Binding unfolded peptides is important for higher order oligomerization [37,58]. Aragón et al., reported that peptide binding stimulated Ire1p clustering, maximized $H A C 1$ recruitment to Ire1p, leading to maximal HACl splicing [58]. Kimata et al., [37] reported that binding to the peptide-binding domain stimulated reorientation of the cytoplasmic domain to maximize splicing activity. A follow-up study by Gardner and Walter revealed that growth on Tm was poor for a yeast mutant (MFY) with decreased affinity for unfolded secretory peptides (see Supplemental Online Materials Figure S7 in [36]). Together, these observations satisfy the criteria to define the sensing function of a stress pathway.

Figure 2. Functional domains of the Ire1p. $\mathrm{LD}=$ Luminal Domain, $\mathrm{TMD}=$ transmembrane domain, $\mathrm{CD}=$ cytoplasmic domain.

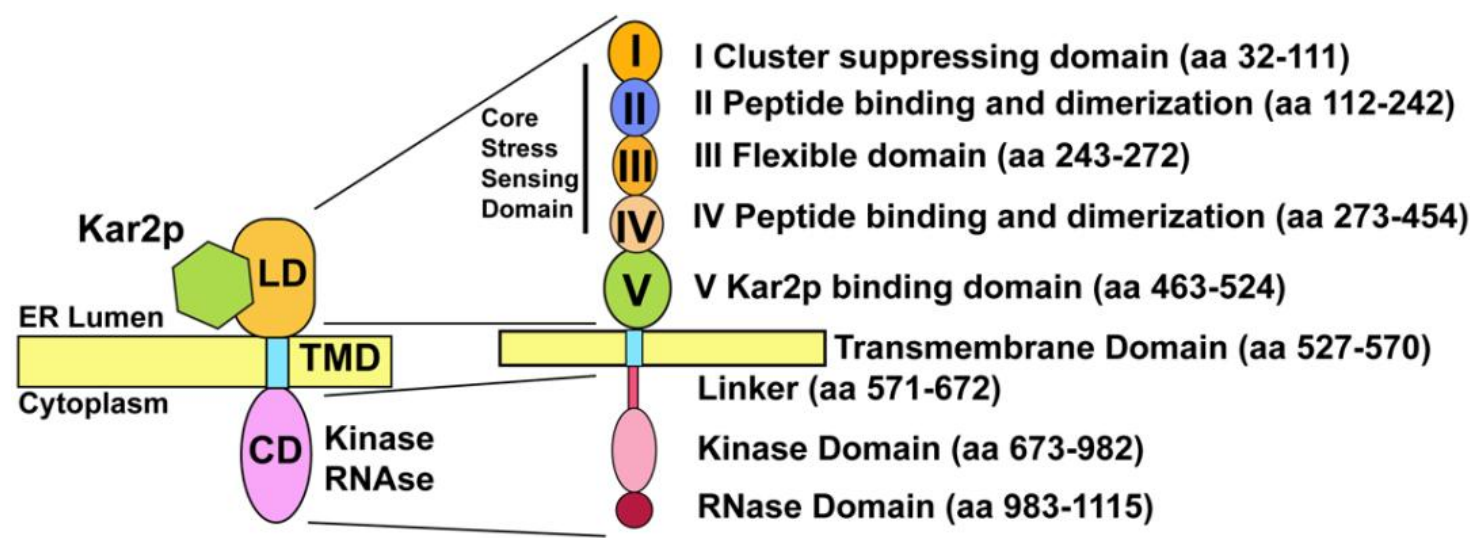

There are caveats to the peptide-binding model. To bind peptides, it seems likely Ire1p would need to be in a minimally dimeric form. Gradient fractionations and co-IPs suggest this is not the case in homeostatic cells [14,66]. Gardner and Walter [36] reported detecting little evidence of monomer binding to peptide. Also, in the Gardner study, the $\triangle \mathrm{MFY}$ mutations decreased the affinity for a substrate $\sim 50$-fold, but only decreased splicing reporter signaling by one half. Similarly, cells expressing a mutant Ire1p lacking a functional peptide binding domain ( $\triangle \mathrm{III})$ still splice $H A C 1 \mathrm{mRNA}$ during DTT or Tm-induced stress, but much less acutely, taking three $\mathrm{h}$ instead of 15-60 min to achieve maximal splicing [59]. The MFY mutant cells in the Gardner study still grew, albeit poorly, unlike cells lacking IRE1, which failed to grow.

The peptide binding story is further complicated in humans. The MHC1-like domain is too narrow to interact with peptides in Randall Kaufman's group's crystal structure of the human IRE1 $\alpha$ luminal domain [60]. They also reported that the putative peptide binding domain was sterically oriented unfavorably towards the ER membrane, the MFY amino acids were not well conserved (YYK) and were buried in the putative peptide binding domain. In addition, Zhou et al. interpreted the crystal data to not favor higher order clustering of the IRE1 $\alpha$ luminal domain. However, a GFP-tagged IRE1 $\alpha$ demonstrably clusters during ER stress [54]. Interestingly, the human IRE1 $\alpha$ luminal domain can functionally replace the Ire1p luminal domain [67,68]. Peptide studies for IRE1 $\alpha$, similar to the Gardner study, will be needed to help resolve the reported differences in the yeast and human systems. 


\section{The Regulatory Role of Kar2p/BiP}

Does Ire1p/IRE1 $\alpha$, alone, directly sense misfolded protein stress and regulate the activation and deactivation of the UPR program? In light of how other misfolded stress sensing pathways include multiple regulatory players, usually in the form of chaperones, it would be surprising if Ire1p does it all.

As with other misfolded stress pathways, Ire1p/IRE1 $\alpha$ binds to a chaperone, specifically Kar2p (the yeast homolog of $\mathrm{BiP}$ ) and BiP. BiP (Kar2p) is the ER Hsp70, an ATPase that works in conjunction with co-chaperones (ERdj Hsp40 homologs and nucleotide exchange factors) to bind nascent and unfolded secretory proteins [69,70]. As unfolded secretory proteins accumulate, Kar2p/BiP binds these client proteins, preventing the unfolded clients from exiting the ER, and potentially poisoning later organelles of the secretory pathway [69-72]. Overexpression of BiP protects against UPR activation [73]. Conversely, decreased levels of BiP increase sensitivity to stress [74]. Thus, BiP appears to be the central node of an ER chaperone and homeostasis network [14,35,69,71,75]. BiP is upregulated 2-6-fold in UPR-adapted cells [76,77] as part of a global program to increase ER chaperone levels and improve the folding environment to substantially increase secretory protein synthesis and flux.

The Kar2p binding site has been mapped to Region V on the luminal domain of Ire1p (Figure 2) [35,49]. Kar2p/BiP releases from Ire1p/IRE $\alpha$ as unfolded proteins accumulate $[14,65,75,78,79]$. BiP release was found to be coincident with the activation of Ire $1 \mathrm{p}$, both in terms of phosphorylation and dimerization $[14,75,79,80]$. In fact, BiP binds and releases from all three of the metazoan UPR stress sensors in a stress-dependent manner [14,16]. Release of BiP from the sensors is necessary for UPR activation [37]. Presumably, BiP/Kar2p sterically blocks IRE1 $\alpha /$ Ire1p oligomerization. Several groups have speculated on a model in which Kar2p/BiP occupancy defines a threshold for Ire1p/IRE1 $\alpha$ activation, such that upon titration of $\mathrm{BiP}$ by unfolded clients, $\mathrm{BiP}$ molecules associated with Ire1p/IRE1 $\alpha$ will be released $[14,49,60,65,75,81]$. Unmasked/unobstructed Ire1p/IRE1 $\alpha$ could now oligomerize and autophosphorylate [14,75].

There are some significant issues with a BiP titration model. First, Kar2p/BiP is one of the most abundant ER chaperones $(\sim 1-10 \mu \mathrm{M})$ [82,83]. Based on a ratio of levels of BiP and the Sec61 translocon, there are probably five to ten copies of BiP per active translocation channels for nascent proteins. One might predict that under only the most extreme stress conditions could the BiP pool become so occupied that the very low levels of Ire1p ( $\sim$ three orders of magnitude less abundant than Kar2p [84]) or IRE1 $\alpha$ would be unable to encounter free BiP [4,14]. Second, the UPR is not an all or none process. The UPR can occur over a spectrum of stressor levels in a dose-response-dependent manner [10,49]. IRE1 $\alpha$ activation can occur at extremely low levels of pharmacologic stressors $[10,85]$.

What happens if Kar2p/BiP binding of Ire1p is disrupted? Binding of Kar2p does not appear to be essential for regulating UPR activation of Ire1p [35,49]. Irelp mutants that poorly bind Kar2p (if at all) $[49,66]$ exhibit a low (three- to five-fold) constitutive level of UPR activation, distinct from a strong Tm or DTT induced stress (20-60-fold). In addition, INO1 transcription is significantly constitutively upregulated in cells expressing an Ire $1 p$ mutant that binds little, if any, Kar2p (Ire $1^{\text {bipless }}$ ) during unstressed conditions. Yet, the Ire $1^{\text {bipless }}$ mutant can be induced 20-fold when stimulated with a misfolded protein stress [35,49]. The "bipless" mutant Irelp does exhibit significantly greater 
sensitivities to ethanol and high temperature [35]. Exposure to ethanol induces a transient activation of wt Ire $1 \mathrm{p}$, but $\Delta \mathrm{V}$ Ire $1 \mathrm{p}$ (another Ire1p lacking the primary Kar2p binding domain, domain $\mathrm{V}$ ) fails to attenuate $H A C 1$ splicing activity. It is unclear why Kar2p binding of Ire1p would be more important for heat or ethanol exposure. A wildly speculative possibility is that unlike DTT or Tm, heat and ethanol also impair general protein folding in the cytoplasm and the more global stress could affect a hypothetical cytoplasmic regulator of Ire1p activation, especially in the absence of Kar2p regulation. Alternatively, the unstructured linker domain of Ire1p could be sensitive to cytoplasmic misfolding conditions. In this scenario, the linker might undergo remodeling or misfold during biogenesis and enable oligomerization. Finally, it is notable that ethanol, heat, and inositol withdrawal could all impact lipid bilayer viscosity. Decreased viscosity could increase Irelp collision rate and resulting activation.

There is some controversy regarding whether the Ire1p mutants are truly free of Kar2p, as Kar2p is reported to be "sticky" in yeast (see next section) [49]. However, no obvious change in the amount of associated or disassociated Kar2 $p$ is observed upon misfolded protein stress-induced activation of the Ire1p mutant $[35,49]$. Interestingly, in mammalian cells, deletion of the BiP-binding domain of IRE1 $\alpha$ results in a molecule that can still be induced to a highly active state by stress [86]. However, the unstressed IRE1 $\alpha$ mutant is constitutively almost half as active as stress-induced wt IRE1 $\alpha$. Thus, BiP appears to play a more significant role in regulating IRE1 $\alpha$ activation than in yeast.

It is unknown whether increasing concentrations of Ire ${ }^{\text {bipless }}$ with peptide-binding mutations exhibit higher levels of constitutive activation. The prediction is that Ire ${ }^{\text {bipless }}$ would tend to activate at much lower levels of overexpression than wild type, while the peptide-binding mutant would either be activated at levels similar to wt Irelp regardless of unfolded peptide levels or would only become strongly constitutively active at much higher levels of mutant expression relative to the wild type. A more substantial mutant lacking both the Kar2p binding domain and a folded peptide-binding domain is not constitutively active and can barely be stimulated to activate, as measured by a $\beta$-galactosidase assay [37].

In yeast BiP-binding mutants, Ire $1^{\text {bipless }}$ and similar $\Delta \mathrm{V}$ or in mammalian cells, IRE $1 \alpha 389$, are not necessarily demonstrably free of Kar2p or BiP-binding $[35,49,86]$. In fact, even stressed wild type HA-tagged Ire1p only partially ( $60 \%)$ releases Kar2p with the robust acute stress of DTT [49]. Thus, the regulatory role of Kar2p/BiP binding to and attenuating Ire1p/IRE1 $\alpha$ requires further investigation.

For wild type Ire1p, increased activation with increased expression either reflects (1) limiting amounts of Kar2 $p$ that can bind and inactivate Ire1p and/or (2) amounts of Kar $2 p$ that can buffer the unfolded secretory protein burden that could potentially bind to higher levels of Ire1p. While Kar2p and Ire1p have different binding specificities for peptides [36], Kar2p binding of unfolded proteins would likely sterically hinder peptide interactions with Ire1p.

In the peptide-binding model, Kar2p has been proposed to buffer the threshold for Ire1p activation, as well as the strength of the UPR [49]. Levels of DTT that barely activate a splicing reporter in wild

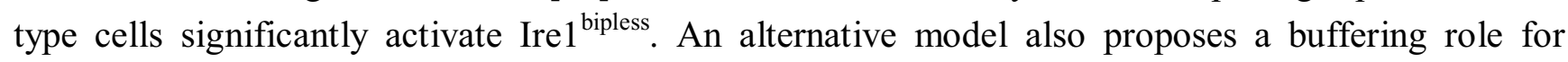
Kar2p binding to modulate Ire1 $p$ activity [65]. However, instead of a role for unfolded protein binding, the strength of Irelp activation depends on the equilibrium between pools of Irelp free inactive and oligomerized active pools. The transition between inactive and active was assumed to be highly cooperative. The dissociation constant of the equilibrium was such that if $70 \%$ of total Irelp were 
released from Kar2p, half of that pool would be in the active state. In this model, the natural tendency of Kar2p-free Ire1p to oligomerize and the concentration of Kar2p bound and unbound Ire1p would be sufficient to regulate activation, independent of unfolded protein binding to Ire1p. The attractiveness of this model derives from its simplicity and the mechanistic similarity to other (i.e. HSF) misfolded protein stress sensing pathways that are strongly regulated by the binding and availability of a chaperone.

\subsection{BiP Association-Stable or Transient?}

Multiple studies report strong evidence that Kar2p strongly associates with Ire1p at steady state $[14,35,79]$. Binding of Ire1p/IRE1 $\alpha$ by Kar2p/BiP has been described as "stable". The stability of the binding of BiP to IRE1 $\alpha$ remains an open question. In light of the normal function of BiP, stable binding would prevent secretory proteins from ever folding. BiP must release from clients for a hydrophobic domain to be able to eventually be buried during the folding process. Bertolotti et al. inferred that the stability of binding occurred because of the in vitro release of BiP from IRE1 $\alpha$ or PERK required addition of ATP [14]. However, BiP association with most clients depends on ATP hydrolysis to switch BiP from a low affinity to a high affinity form and release of hydrolyzed ADP from $\mathrm{BiP}$ to return to a low affinity form [72,87]. It is, therefore, not surprising that a purified BiP complex would not undergo significant release of a client. Otherwise one would anticipate that BiP-client complexes would be difficult to immunoprecipitate in the absence of crosslinkers. That said, most secretory proteins only transiently interact with BiP as an intermediate step in folding. The ability of Ire1p/IRE1 $\alpha$ to continue to interact with Kar2p/BiP suggests, at the very least, that Ire $1 \mathrm{p} / \mathrm{IRE} 1 \alpha$ contains a high affinity BiP binding site and/or an unfoldable domain. The Kar2p/BiP binding domain is unstructured in crystallography studies $[38,60]$. A potentially comparable situation occurs in antibody folding.

The immunoglobulin heavy chain contains an unfolded high affinity BiP binding site that only releases from $\mathrm{BiP}$ in the presence of the light chain binding partner [88]. BiP/Kar2p could bind IRE1 $\alpha /$ Ire $1 p$ with an affinity comparable to that of its binding of the $\mathrm{C}_{\mathrm{H}} 1$ domain of immunoglobulin heavy chain $\left(\mathrm{C}_{\mathrm{H}} 1\right), \sim 2.5-12 \mathrm{M}[5,88]$. This relatively tight association appears to be highly stable and BiP does not detectably cycle, only being released in the presence of the light chain, the partner for the heavy chain [88]. The exact mechanistic step that enables BiP to release from $\mathrm{C}_{\mathrm{H}} 1$ is not entirely clear [5]. Formation of an exposed disulfide bond in $\mathrm{C}_{\mathrm{H}} 1$ is essential for discontinuation of BiP binding. The unstructured regions [35,49] of Ire1p/IRE1 $\alpha$ that associate with BiP lack cysteines, though there are additional cysteines in the luminal domain. However, a luminal domain mutated for cysteine residues remains functional, if a little more active in signaling compared to wild type [86]. If the stable binding model is correct, stress would somehow affect an IRE1 $\alpha$ folding step to alter BiP affinity and this event would have to occur for multiple IRE1 $\alpha$ molecules to collide and oligomerize.

What if Kar2p/BiP does cycle on and off Ire1p/IRE1 $\alpha$ in cells? The experimental evidence for an absence of cycling is not iron clad. If BiP cycles on and off of Ire $1 \mathrm{p} / \mathrm{IRE} 1 \alpha$, how could the vast excess of free BiP play a role in a tunable system? One possibility is that little free $\mathrm{BiP}$ exists at steady state in cells. Surprisingly, there is no definitive study of this problem. It is unclear how many nascent proteins require BiP assistance for normal folding. Why would a cell keep little BiP in reserve for increased levels of unfolded proteins? This would place the cell at extreme risk of accumulation of aggregating 
misfolded proteins in the event of even a modest ER stress. A body of evidence suggests that the pool of $\mathrm{BiP}$ is only partially occupied at steady state. There is a substantial change in the size and fraction of BiP-containing complexes between homeostatic and acutely stressed cells [53,89-91]. This reflects increased binding of clients and a change in the size of client-containing complexes that could result from multiple chaperones binding to a single client, as can occur during stress [92].

If $\mathrm{BiP}$ does cycle, then one of the key mysteries of IRE1 $\alpha$ regulation becomes simpler to resolve. No special regulatory steps would be required to compete BiP off of IRE1 $\alpha$. Accumulating misfolded secretory proteins would simply titrate the pool of free BiP, making it unavailable to bind and inactivate Ire1p/IRE1 $\alpha$. What about the pool of excess BiP of three orders of magnitude? The answer to this question depends on the extent of BiP occupancy at steady state. Biochemical and live cell assays of BiP occupancy suggest that a substantial pool of BiP is not client-bound or that client association is highly transient and clients are comparatively small [53,89-91]. During unfolded protein accumulation, clients can bind multiple chaperones, resulting in extremely large complexes and decreasing BiP availability.

If $\mathrm{BiP}$ does not cycle, why not and what would regulate $\mathrm{BiP}$ to release from IRE1 $\alpha$ ? Two major ways to prevent BiP from cycling would be to either (1) sterically hinder BiP access to the nucleotide exchange factor GRP170, which enables BiP to shift to a low affinity state and release clients and/or (2) post-translationally modify $\mathrm{BiP}$ bound to $\alpha$. While IRE1 $\alpha$ could sterically shield BiP from regulatory cofactors (i.e., GRP170 or ERdj3), it is unclear what would then make BiP more accessible during conditions of increasing levels of misfolded secretory proteins.

Reports from the 1990s, as well as a recent study by Chambers et al., have shown that BiP is posttranslationally modified in the metazoan ER lumen by ADP-ribosylation [93-98]. The modification converts BiP to a low affinity binding state and the modification is likely to be regulated by unidentified resident ER enzymes [93]. In stressed conditions, minimal ADP ribosylated BiP was detected in professional secretory cells [93,97] The current model of the processing of ADP-ribosylation is that only unoccupied BiP will be modified and inactivated [93]. During low client levels, ADP ribosylation would inactivate a pool of BiP, decreasing demands on ATP and decreasing retention of otherwise foldable secretory proteins [93]. As unfolded proteins accumulate constitutively de-ribosylated BiP becomes available to bind accumulating clients. Treatment with translational inhibitors or decreased translation in fasted rat pancreas leads to one third to half of BiP becoming ADP ribosylated [93]. Only when client levels decrease, will levels of ADP ribosylated BiP begin to increase again. Perhaps a decrease in available BiP to ribosylate could increase the probability that $\mathrm{BiP}$ bound to IRE1 $\alpha$ could become deribosylated and lead to release from IRE1 $\alpha$. It would be interesting to determine whether a nonribosylatable form of $\mathrm{BiP}$ can bind or release from IRE1 $\alpha$. Also, it is unclear whether ADP ribosylation of BiP occurs in single cell organisms.

The concentration of IRE1 $\alpha /$ Irelp in the ER membrane is an additional regulator of UPR activation. If most IRE $1 \alpha$ is monomeric at steady state and expressed at very low levels, then BiP regulation gains further complexity, because Ire1p/IRE1 $\alpha$ activation becomes an exceptionally low probability event. For any single IRE1 $\alpha$ dimerization event, a BiP-free IRE1 $\alpha$ molecule would need to diffuse throughout the tortuous network of ER tubule membranes $\left(\sim 20,000 \mu \mathrm{m}^{2}\right)$ [99] before potentially encountering another free IRE1 $\alpha$ molecule. As free BiP increasingly binds to clients during unfolded protein accumulation, the probability of free IRE1 $\alpha$ collisions begins to increase 
dramatically. Interestingly, Bertolotti et al. observed a substantial increase in BiP-bound IRE1 $\alpha$ in cells overexpressing BiP [14]. Overexpressed BiP could decrease the probability that IRE1 $\alpha$ will fail to encounter active BiP during normally stressful conditions.

Together, these data predict that a calculable threshold of clients is required for productive activation. Consistent with this model, increasing UPR sensors or decreasing BiP levels increases UPR activation, while increasing BiP will decrease stress sensitivity [35].

Another problem, how BiP associates with Ire1p/IRE1 $\alpha$, remains unresolved. The first question is whether BiP binds via its substrate-binding domain or some other region. The answer will impact the second problem of how BiP binding and release are regulated. Some studies suggest that BiP/Kar2p binds IRE $1 \alpha /$ Ire $1 p$ via the BiP's substrate-binding domain. If correct, binding to Ire $1 p$ should resemble binding to other clients. Studies $[16,35,68]$ have examined the effects of ATP hydrolysis mutants or in one case, client-binding mutants of Kar2p/BiP on regulated association with Ire1p/IRE1 $\alpha$ [35]. The particular ATPase mutants are trapping mutants, as they cannot effectively release from clients, while substrate-binding mutants not only appear to not bind the UPR sensor, they cannot bind unfolded proteins, leading to exacerbated stress in yeast backgrounds lacking a wild type copy of $K A R 2$. Thus, it is unclear whether substrateless Kar2p really cannot bind UPR sensors or if the constitutive stress resulting from the absence of functional Kar2p prevents the mutant from ever binding at the nonpermissive temperature. To resolve this, one could express a substrate-binding mutant of Kar2p (kar2-133) in trans in yeast endogenously expressing wild type Kar2p. At the permissive and nonpermissive temperatures, Ire1p could be immunoprecipitated from these cells and the amounts of wt and epitope tagged mutant Kar2p on Ire1p could be quantified. The endogenous Kar2p will maintain an unstressed environment, preventing global release of Kar2p from Ire1p. If mutant Kar2p binds Ire1p, the result would support an alternative model by Todd Corlett et al. [100] that Kar2p binds via a lobe on its ATPase domain to Ire1p.

The Ire1p-binding site for Kar2p has been mapped to a luminal region adjacent to the transmembrane domain [35]. This region is unstructured $[38,60]$ in crystallography studies, similar to a BiP client, and suggests that BiP binding could be via the substrate-binding domain.

\section{Ire1p Activation Independent of Unfolded Proteins: The Inositol Sensing Problem}

Despite impressive efforts to characterize the role of $\mathrm{BiP}$ and peptide binding in the regulation of UPR activation, neither group of molecules appears to be the whole story. IRE1 $\alpha$ can be activated by a small molecule targeted to its cytoplasmic domain [63]. Liu et al. [80], reported that replacing the luminal domain of Ire1p with a dimerizing leucine zipper motif (Maf or Jun) resulted in a constitutively weakly active Irelp that could be substantially stimulated by ER stress (Tm) [80]. Whether peptide binding by the luminal domain is important during inositol depletion remains unclear. Constitutively dimeric Ire1p (with the luminal domain replaced with the Gen4p bZIP domain) is inactive, but responsive to inositol depletion, which leads to clustering [37,59]. In addition, disruption of the peptide-binding domain ( $\Delta \mathrm{III}$ ) decreases sensitivity to DTT or Tm, but not inositol [59]. Wild type activation following inositol withdrawal is much slower than with unfolded protein stressors. Thus, there appears to be a way to stimulate Ire $1 p$ independent of the binding of unfolded proteins or 
release of $\mathrm{BiP}$. Two recent studies further validate this phenomenon in relation to the atypical ER stress, inositol depletion.

Although Ire1p was first identified as an essential gene to prevent inositol auxotrophy [27-29,101], the connection between Ire1p and inositol regulation remains poorly understood. Ire1p's target mRNA, $H A C 1$, is also required for yeast growth in inositol depletion conditions [27,32]. Irelp activation by inositol depletion mirrors steps for unfolded protein activation Irelp clustering [59], phosphorylation [52], splicing of $H A C 1$ [101,102], and an attenuation phase [49].

IREI and HACl are essential for yeast growth on inositol depletion media [27]. It remains a mystery why the UPR is required for growth in inositol depletion conditions. The relationship between Irelp and the inositol pathway, which is regulated by INO1 transcription, is unclear. Misfolded protein stresses significantly upregulate INOI transcription, as well as components of the INOI pathway [101]. Similarly, inositol depletion is accompanied by Ire1p activation and HAC1 splicing [101]. Interestingly, Irelp modification of $H A C l$ is not necessarily required for growth in the absence of inositol [103]. Unspliced Hac1p has very low activity on UPR elements. It remains possible that Haclp and Ire1p could have alternative functions for inositol depletion stress. Haclp upregulates INO2 and INO4 levels [104] and reportedly enhances transcription of INOI [105]. UPR activation could also be a response to upregulation of INOI targets, which include ER membrane proteins.

In contrast to the peptide binding Irelp activation model, inositol depletion does not require the Ire1p luminal domain. Promlek et al. reported that inositol depletion activates Ire1p lacking the peptide-binding domain [59]. In fact, the entire luminal domain of Ire1p can be replaced with the bZIP oligomerization domain of Gcn4p. The construct exhibits low constitutive activation, but can be stimulated substantially by inositol depletion [59]. Tm and DTT treatments can stimulate the same reporter, though activation is significantly slower than with wild type Ire1p [59]. Until recently, it has been unclear whether inositol depletion causes misfolded secretory proteins to accumulate in the ER. This does not appear to be the case. Lajoie et al.[89], found that inositol depletion is not associated with increased occupancy of Kar2p. Together, these data strongly suggest that Ire1p can activate independently of unfolded peptide sensing.

How inositol depletion and atypical stresses activate Ire1p remains a fundamental problem for the UPR field. Potential models include (1) a detector model in which a protein cofactor senses changes in lipids or metabolites and activates Ire1p through stimulated oligomerization and (2) a direct detection of a lipid metabolite or lipid by Ire1p that would induce a conformational change in the cytoplasmic domain, enabling oligomerization (Figure 3).

\subsection{Ire1p or Protein Co-factor Detects Inositol Changes Model}

Besides Irelp luminal domain recognizing unfolded peptides, other Ire $1 p$ domains may recognize other types of substrates. For example, Contreras et al., recently described the ability of a protein's transmembrane domain (TMD) to recognize sphingolipids [106]. In addition, the flavanol Quercetin [63] can bind the Ire1p cytoplasmic domain and potentiate Ire1p activation.

However, there is a conceptual problem with a cytoplasmic partner activating Ire $1 p$. If the Irelp luminal domain normally depends on peptide binding and release of Kar2p for maximal activation, it is unclear how the cytoplasm might trigger Kar2p release from the luminal domain, especially in the 
absence of obvious unfolded protein levels [89]. If Kar2p actually cycles on and off Ire1p, a cytoplasmic factor could conceivably forcibly bring two Ire $1 p$ molecules together in an orientation that would preclude rebinding of Kar2p. Alternatively, a co-factor could be an integral membrane protein with a luminal domain capable of stimulating Kar2p release from Ire1p. It would be interesting to determine whether, as with unfolded protein stress, increased Kar2p levels have any effect on regulation of Ire1p activation during inositol withdrawal.

Figure 3. Alternative Irelp activation Models. (A) Co-factor model. Upon inositol depletion, a membrane-associated or integral membrane protein accumulates in the ER membrane. The factor has affinity to the Ire1p cytoplasmic domain and enhances binding of pairs of Ire1p as Kar2p dissociates during normal binding and release or specifically binds and oligomerizes newly synthesized Kar2p-free Ire1p. (B) Direct sensing model. Irelp detects changes in inositol levels and allosterically reorganizes or partially misfolds to increase affinity of the cytoplasmic domains leading to oligomerization and activation. Upon restoration of homeostasis Ire1p could resume the inactive conformation.
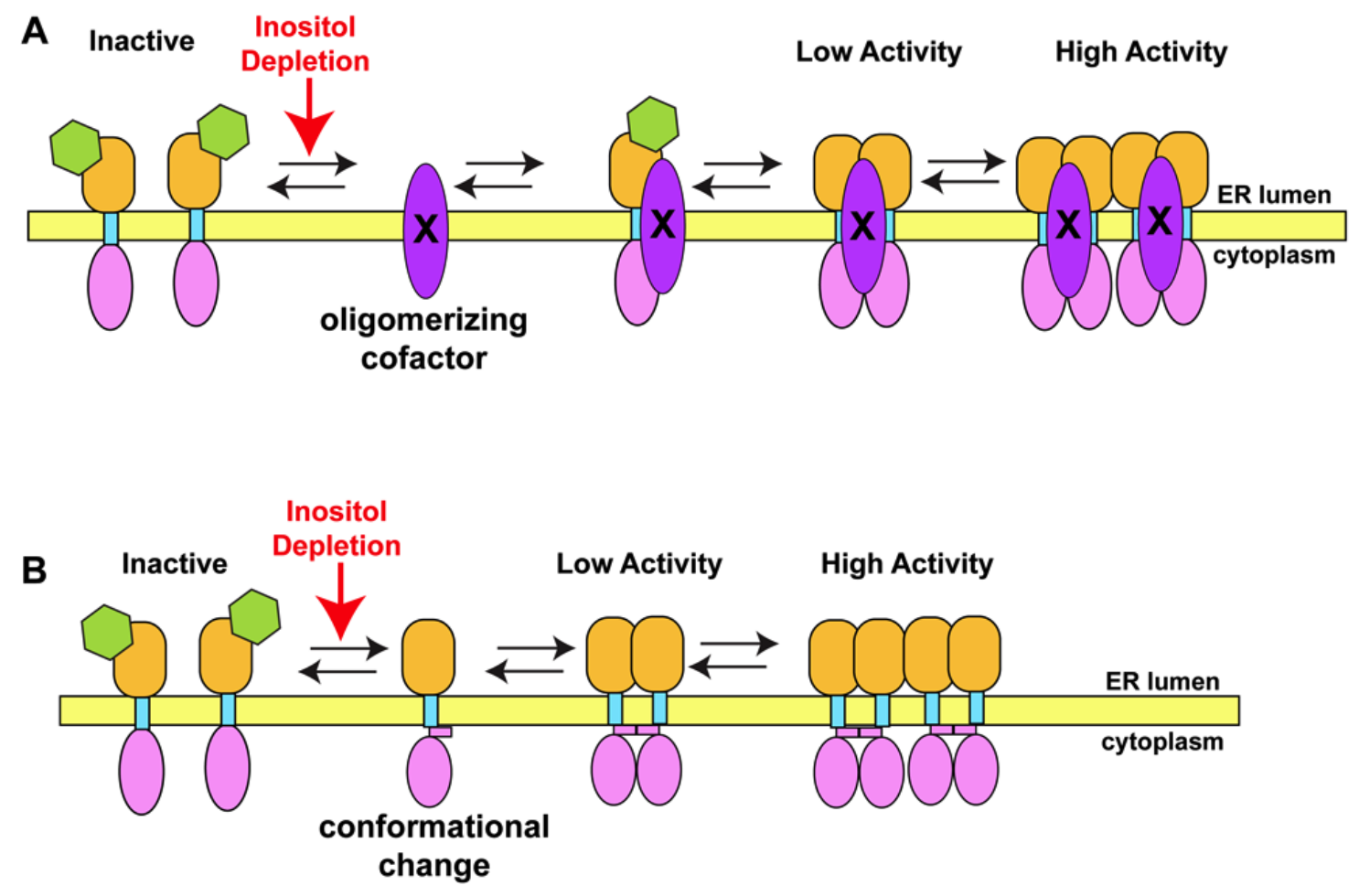

\subsection{How Might Irelp Be Activated During Inositol Withdrawal or in the Absence of a Luminal Domain?}

It is unknown what domain(s) of Ire1p are necessary for sensing inositol depletion and/or activation during inositol depletion. Thus, the cytoplasmic domain and/or a partner protein for the cytoplasmic domain are the most logical candidates. Identifying relevant regions of the cytoplasmic domain may prove difficult. Deletion of less than $10 \%$ of the cytoplasmic $\mathrm{COOH}$-terminus of Ire1p renders the protein inactive $[52,55]$. Chimeras with human IRE1 $\alpha$ domains may prove fruitful.

What about a cytoplasmic sensor of inositol levels and/or a regulator of Ire1p activation? Hetz and colleagues have described how mammalian cytoplasmic proteins can bind and regulate IRE1 $\alpha$ 
activity [107-109]. In addition, Marcu et al., described how Hsp90 binding to the cytoplasmic domain of IRE1 $\alpha$ decreases the rate of IRE1 $\alpha$ turnover [110]. It is unclear whether Hsp90 (Hsc82 or Hsp82) plays a similar role for Ire1p in yeast. The existence of cytoplasmic IRE1 $\alpha$ co-factors establishes a precedent for IRE1 function and regulation independent of unfolded secretory protein levels in the ER lumen. In addition, Marcu et al., reported binding of IRE1 $\alpha$ by GRP94, the luminal Hsp90 homolog [110]. As HSF1 binds Hsp90, a role for GRP94 certainly remains a possibility. However, yeast lacks a luminal Hsp90. Yet, the human IRE1 $\alpha$ luminal domain can replace the yeast Ire1p luminal domain and retain robust stress-inducible activation with only a trace of unstressed constitutive activation [80]. Thus, GRP94 does not appear to be critical for negative regulation of IRE $1 \alpha$.

How might a cytoplasmic co-factor regulate Ire1p during inositol depletion? Given the importance of oligomerization for Ire1p activation, a cytoplasmic clustering factor for Ire1p makes sense. The molecule would require some sort of activation to become an Ire1p partner and binding to Ire1p could be transient to permit downregulation of Ire1p activity. Coupled with the low abundance of Ire1p, such a molecule could be biochemically challenging to detect. Furthermore, if the clustering factor were an essential protein with other inositol-related functions, it would be difficult to pick such a needle out of a haystack.

How would an alternative stress stimulate release of BiP from Irelp? If the stress perturbed BiP function, such as calcium depletion [111], this could lead to Kar2p release. Another possibility is that the hypothetical regulatory molecule could bind one Irelp and in rare, but still with sufficiently frequent probability, cases capture another Ire1p shortly after a Kar2p dissociates. Once bound, the co-factor would need to facilitate Ire1p activation, perhaps by binding to a site similar in function to the quercetin-binding site on Ire1p that activate Ire1p RNase activity [63]. The quercetin binding site is not a candidate, as Promlek et al., mutated those residues and observed no difference in inositol depletion mediated activation [59]. The slow accumulation of activated Ire1p molecules would make the process more linear, and thus less acute, than a more familiar misfolded protein stress. Such a model would be consistent with studies to date and could serve as a template for other ways to activate or regulate the UPR.

\section{Ire1p Inactivation}

Just as it has been challenging to understand how Ire1p/IRE1 $\alpha$ can be activated by distinct stresses and to varying degrees, attenuation and deactivation of the UPR represent similarly difficult problems. First, there is the general matter of the steps of deactivation. Does it proceed by gradual dissociation of dimers from clusters followed by monomerization? Do individual monomers break off of clusters? Are peptides competed off of luminal domains by increasing levels of Kar2p/BiP? Does attenuation correlate directly with increased Kar2p/BiP levels? If so, is there a threshold level of Kar2p/BiP for attenuation? Does overall BiP occupancy decrease detectably in Ire1p attenuating cells?

Perhaps the most puzzling question is, how does Ire1p/IRE $1 \alpha$ attenuate/deactivate in cells in the continued presence of an active stressor $[19,44]$ ? Lin et al., reported that human cell lines attenuated Xbpl splicing after $8 \mathrm{~h}$ of exposure to Tm, that the Tm did not lose potency, and other arms of the UPR (especially PERK) continued to remain active [44]. If the PERK luminal domain can substitute 
for the IRE1 $\alpha$ luminal domain [14,80], then attenuation is likely to reflect inactivation at the cytoplasmic domain of IRE1 $\alpha$. The groups of Peter Walter and Maho Niwa reported that increasing levels of autophosphorylation are believed to enhance repulsion of Irelp monomers from clusters $[19,20]$, and this repulsion could drive inactivation of the UPR. Newly upregulated levels of Kar2p/BiP could be sufficiently available to bind unfolded secretory proteins, competing them away from Ire1p oligomers, and also directly binding free Ire1p monomers. Interestingly, studies by our group showed little change in Kar2p-sfGFP mobility during the time period when the UPR attenuates (4 h), whereas Kar2p mobility fully recovered by $16 \mathrm{~h}$ [89]. At $4 \mathrm{~h}$ of exposure to a robust dose of Tm, splicing reporter fluorescence had increased maximally [89]. A phosphatase could then potentially reset the status of the Ire1p monomers to a deactivated state [112,113]. It is likely that FRAP diffusion measurements are not sufficiently sensitive to detect small changes in Kar2p availability, i.e., an increase of $10 \%$ of unbound Kar2p molecules. However, if relatively small changes in Kar2p BiP availability govern Ire1p inactivation, it becomes a little more difficult to understand how the UPR can be tuned to a wide range of levels of stressors. If peptide binding were the key regulator, then increasing levels of chaperones entering the ER would titrate the available pool of unfolded proteins due to higher levels of chaperones and increased competition by UPR upregulated mRNAs for translocation channels. That is, the misfolded protein mRNA becomes a smaller percentage of total mRNA and comparatively less misfolded secretory protein would be produced. How attenuation would work for the constructs that have luminal domains replaced with bZIP dimerization domains that cannot bind peptides or BiP is unclear. While the constructs do not appear to be detrimental in the way that kinase inactive Irelp mutants impair cell recovery during stress $[19,20,80]$, it has not been reported whether the constructs attenuate and if so, when. If a cytoplasmic regulator enhances Ire $1 \mathrm{p}$ oligomerization during inositol depletion, restoration of homeostasis could result in release/turnover of the regulator, followed by dispersal of Ire $1 p$.

Once homeostasis (a manageable level of unfolded proteins) is restored, Ire1p/IRE1 $\alpha$ would disassociate as increased levels of Kar $2 p$ competed for unfolded secretory peptides. The increasingly extensive phosphorylation of Ire1p during activation [52] has been proposed as a mechanism for Ire1p disassociation. The negative charges could repulse Ire1p molecules away from each other and one or more phosphatases (Dcr2p and/or Ptc2p) would return the Ire1p molecules to a resting and activatable state $[112,113]$.

\section{Conclusion}

The emerging picture of Ire1p regulation is that peptide binding to the MHC1-like groove can enhance the rate of Irelp activation and its splicing activity in yeast. Yet, peptide binding does not appear to be essential for Ire1p function. UPR activating conditions exist where no apparent increase in unfolded protein levels occur.

It is striking how many similarities and differences there are between Ire $1 \mathrm{p} / \mathrm{IRE} 1 \alpha$ and other unfolded protein response pathways. Ire1p, $\sigma 32$, and HSF all interact with chaperones to help regulate activity. HSF and $\sigma 32$ directly regulate transcription of the chaperone that binds them, while Ire1p/IRE $1 \alpha$ regulates processing of the transcription factor that upregulates Kar2p/BiP. HSF, $\sigma 32$, and IRE $1 \alpha$ are all regulated directly by chaperone binding and release, apparently through changing 
levels of unfolded proteins that can interact with the regulatory chaperone. Irelp's regulation remains more controversial. Whether Kar2p binding is very important requires resolving, as does the question whether Ire $1 p$ mutants are truly free of associated Kar2p. The peptide-binding model has considerable supporting evidence, though the UPR can clearly be activated without the Ire1p luminal domain. It is also surprising that IRE $1 \alpha$ could be so radically different in mechanism compared to Ire $1 p$. It remains to be determined whether IRE1 $\alpha$ can bind unfolded peptides, but the crystal structure either reflects a closed form of the peptide-binding domain [36] or could represent the evolutionary remnants of a mechanism unfavorable for metazoans.

Despite considerable sequence conservation in IRE1 homologs, the UPR, even in single celled fungi, can exhibit surprising diversity. Recently the laboratory of Jonathan Weissman noted that Schizosaccharomyces pombe expresses Ire1, but lacks $H A C l$ in its genome. Importantly, strong genetic links between Ire1p and the $S$. pombe UDP-glucose-glycoprotein glucosyltransferase and calnexin were identified [114]. Similar links were not detected between IRE1 and the S. cerevisiae homologs. Thus, the UPR appears to be malleable. The capacity for RIDD remains to be explored in fungi.

How Irelp is activated is likely to be important for the resulting UPR. Thibault et al., recently reported that deletions of different important ER genes led to comparable upregulation of the UPR transcriptional reporter assay, but resulted in gene regulation profiles different from each other and a standard DTT stress [64] This could reflect activation of additional stress pathways, such as the Heat Shock pathway [115]. Alternatively, just as acute stress and inositol depletion can both result in comparable levels of UPR activation, but at different rates, how stresses activate the UPR may be critical for predicting cellular outcomes.

The complexity of UPR regulation in yeast hints at even richer possibilities in human cells. With five sensors, (IRE1 $\alpha$ and $\beta$, PERK, and ATF6 $\alpha$ and $\beta$ ), evidence of multiple cytoplasmic regulators of UPR sensors [107-110], differences in sensitivities to distinct stresses [116], and recent studies hinting at the abilities of novel sensing mechanisms (i.e., ATF6 appears to detect transmembrane domains [117]), there is little doubt that the human UPR will hold many surprises. Understanding this complexity will become increasingly important as new studies identify UPR regulatory roles beyond the management of unfolded protein levels [22]. Increasing connections are being recognized between dysregulated UPR and human disease. Alternative UPR regulatory modes are providing new therapeutic targets at additional sites on the sensors and modulation of protein co-factors.

\section{Acknowledgments}

Thanks to Patrick Lajoie for helpful conversations and reading of the manuscript. ELS was supported by NIH Grants R01GM086530 and 5R01GM087985. The content is solely the responsibility of the author and does not necessarily represent the official views of the NIGMS or the NIH.

\section{Conflict of Interest}

The author declares no conflict of interest. 


\section{References}

1. van Anken, E.; Braakman, I.; Craig, E. Versatility of the endoplasmic reticulum protein folding factory. Crit. Rev. Biochem. Mol. Biol. 2005, 40, 191-228.

2. Kowarik, M.; Kung, S.; Martoglio, B.; Helenius, A. Protein folding during cotranslational translocation in the endoplasmic reticulum. Mol. Cell. 2002, 10, 769-778.

3. Brodsky, J.L.; Skach, W.R. Protein folding and quality control in the endoplasmic reticulum: Recent lessons from yeast and mammalian cell systems. Curr. Opin. Cell. Biol. 2011, 23, 464-475.

4. Walter, P.; Ron, D. The unfolded protein response: from stress pathway to homeostatic regulation. Science 2011, 334, 1081-1086.

5. Feige, M.J.; Groscurth, S.; Marcinowski, M.; Shimizu, Y.; Kessler, H.; Hendershot, L.M.; Buchner, J. An unfolded CH1 domain controls the assembly and secretion of IgG antibodies. Mol. Cell. 2009, 34, 569-579.

6. Ron, D.; Walter, P. Signal integration in the endoplasmic reticulum unfolded protein response. Nat. Rev. Mol. Cell. Biol. 2007, 8, 519-529.

7. Bernales, S.; Papa, F.R.; Walter, P. Intracellular signaling by the unfolded protein response. Annu. Rev. Cell. Dev. Biol. 2006, 22, 487-508.

8. Malhotra, J.D.; Kaufman, R.J. The endoplasmic reticulum and the unfolded protein response. Semin. Cell. Dev. Biol. 2007, 18, 716-731.

9. Yoshida, H. ER stress and diseases. FEBS J. 2007, 274, 630-658.

10. Rutkowski, D.T.; Arnold, S.M.; Miller, C.N.; Wu, J.; Li, J.; Gunnison, K.M.; Mori, K.; Sadighi Akha, A.A.; Raden, D.; Kaufman, R.J. Adaptation to ER stress is mediated by differential stabilities of pro-survival and pro-apoptotic mRNAs and proteins. PLoS Biol. 2006, 4, e374.

11. Kozutsumi, Y.; Segal, M.; Normington, K.; Gething, M.J.; Sambrook, J. The presence of malfolded proteins in the endoplasmic reticulum signals the induction of glucose-regulated proteins. Nature 1988, 332, 462-464.

12. Harding, H.P.; Novoa, I.; Zhang, Y.; Zeng, H.; Wek, R.; Schapira, M.; Ron, D. Regulated translation initiation controls stress-induced gene expression in mammalian cells. Mol. Cell. 2000, 6, 1099-1108.

13. Schuck, S.; Prinz, W.A.; Thorn, K.S.; Voss, C.; Walter, P. Membrane expansion alleviates endoplasmic reticulum stress independently of the unfolded protein response. J. Cell. Biol. 2009, 187, 525-536.

14. Bertolotti, A.; Zhang, Y.; Hendershot, L.M.; Harding, H.P.; Ron, D. Dynamic interaction of BiP and ER stress transducers in the unfolded- protein response. Nat. Cell. Biol. 2000, 2, 326-332.

15. Lee, A.H.; Iwakoshi, N.N.; Glimcher, L.H. XBP-1 regulates a subset of endoplasmic reticulum resident chaperone genes in the unfolded protein response. Mol. Cell. Biol. 2003, 23, 7448-7459.

16. Shen, J.; Chen, X.; Hendershot, L.; Prywes, R. ER stress regulation of ATF6 localization by dissociation of BiP/GRP78 binding and unmasking of Golgi localization signals. Dev. Cell. 2002, 3, 99-111.

17. Rutkowski, D.T.; Kaufman, R.J. A trip to the ER: Coping with stress. Trends Cell. Biol. 2004, 14, 20-28. 
18. Tabas, I.; Ron, D. Integrating the mechanisms of apoptosis induced by endoplasmic reticulum stress. Nat. Cell. Biol. 2011, 13, 184-190.

19. Chawla, A.; Chakrabarti, S.; Ghosh, G.; Niwa, M. Attenuation of yeast UPR is essential for survival and is mediated by IRE1 kinase. J. Cell. Biol. 2011, 193, 41-50.

20. Rubio, C.; Pincus, D.; Korennykh, A.; Schuck, S.; El-Samad, H.; Walter, P. Homeostatic adaptation to endoplasmic reticulum stress depends on Ire1 kinase activity. J. Cell. Biol. 2011, 193, 171-184.

21. Ozcan, U.; Yilmaz, E.; Ozcan, L.; Furuhashi, M.; Vaillancourt, E.; Smith, R.O.; Gorgun, C.Z.; Hotamisligil, G.S. Chemical chaperones reduce ER stress and restore glucose homeostasis in a mouse model of type 2 diabetes. Science 2006, 313, 1137-1140.

22. Rutkowski, D.T.; Hegde, R.S. Regulation of basal cellular physiology by the homeostatic unfolded protein response. J. Cell. Biol. 2010, 189, 783-794.

23. Sierra, F. Is (your cellular response to) stress killing you? J. Gerontol. 2006, 61, 557-561.

24. Hartl, F.U.; Bracher, A.; Hayer-Hartl, M. Molecular chaperones in protein folding and proteostasis. Nature 2011, 475, 324-332.

25. Arsene, F.; Tomoyasu, T.; Bukau, B. The heat shock response of Escherichia coli. Int. J. Food Microbiol. 2000, 55, 3-9.

26. Anckar, J.; Sistonen, L. Regulation of HSF1 function in the heat stress response: Implications in aging and disease. Annu. Rev. Biochem. 2011, 80, 1089-1115.

27. Nikawa, J.; Yamashita, S. IRE1 encodes a putative protein kinase containing a membranespanning domain and is required for inositol phototrophy in Saccharomyces cerevisiae. Mol. Microbiol. 1992, 6, 1441-1446.

28. Cox, J.S.; Shamu, C.E.; Walter, P. Transcriptional induction of genes encoding endoplasmic reticulum resident proteins requires a transmembrane protein kinase. Cell 1993, 73, 1197-1206.

29. Mori, K.; Ma, W.; Gething, M.J.; Sambrook J. A transmembrane protein with a cdc2+/CDC28-related kinase activity is required for signaling from the ER to the nucleus. Cell 1993, 74, 743-756.

30. Li, W.W.; Alexandre, S.; Cao, X.; Lee, A.S. Transactivation of the grp78 promoter by $\mathrm{Ca}^{2+}$ depletion. A comparative analysis with A23187 and the endoplasmic reticulum $\mathrm{Ca}(2+)$-ATPase inhibitor thapsigargin. J. Biol. Chem. 1993, 268, 12003-12009.

31. Bork, P.; Sander, C. A hybrid protein kinase-RNase in an interferon-induced pathway? FEBS Lett. 1993, 334, 149-152.

32. Sidrauski, C.; Cox, J.S.; Walter, P. tRNA ligase is required for regulated mRNA splicing in the unfolded protein response. Cell 1996, 87, 405-413.

33. Yoshida, H.; Matsui, T.; Yamamoto, A.; Okada, T.; Mori, K. XBP1 mRNA is induced by ATF6 and spliced by IRE1 in response to ER stress to produce a highly active transcription factor. Cell 2001, 107, 881-891.

34. Oikawa, D.; Kimata, Y.; Takeuchi, M.; Kohno, K. An essential dimer-forming subregion of the endoplasmic reticulum stress sensor Ire1. Biochem. J. 2005, 391, 135-142.

35. Kimata, Y.; Oikawa, D.; Shimizu, Y.; Ishiwata-Kimata, Y.; Kohno, K. A role for BiP as an adjustor for the endoplasmic reticulum stress-sensing protein Ire1. J. Cell. Biol. 2004, 167, 445-456. 
36. Gardner, B.M.; Walter, P. Unfolded proteins are Ire1-activating ligands that directly induce the unfolded protein response. Science 2011, 333, 1891-1894.

37. Kimata, Y.; Ishiwata-Kimata, Y.; Ito, T.; Hirata, A.; Suzuki, T.; Oikawa, D.; Takeuchi, M.; Kohno, K. Two regulatory steps of ER-stress sensor Ire1 involving its cluster formation and interaction with unfolded proteins. J. Cell. Biol. 2007, 179, 75-86.

38. Credle, J.J.; Finer-Moore, J.S.; Papa, F.R.; Stroud, R.M.; Walter, P. On the mechanism of sensing unfolded protein in the endoplasmic reticulum. Proc. Natl. Acad. Sci. USA 2005, 102, 18773-18784.

39. Cox, J.S.; Walter, P. A novel mechanism for regulating activity of a transcription factor that controls the unfolded protein response. Cell 1996, 87, 391-404.

40. Hollien, J.; Weissman, J.S. Decay of endoplasmic reticulum-localized mRNAs during the unfolded protein response. Science 2006, 313, 104-107.

41. Hollien, J.; Lin, J.H.; Li H; Stevens, N.; Walter, P.; Weissman, J.S. Regulated Ire1-dependent decay of messenger RNAs in mammalian cells. J. Cell. Biol. 2009, 186, 323-331.

42. Han, D.; Lerner, A.G.; Vande, W.L.; Upton, J.P.; Xu, W.; Hagen, A.; Backes. B.J.; Oakes, S.A.; Papa, F.R. IRE1alpha kinase activation modes control alternate endoribonuclease outputs to determine divergent cell fates. Cell 2009, 138, 562-575.

43. Iwawaki, T.; Hosoda, A.; Okuda, T.; Kamigori, Y.; Nomura-Furuwatari, C.; Kimata, Y.; Tsuru, A.; Kohno, K. Translational control by the ER transmembrane kinase/ribonuclease IRE1 under ER stress. Nat. Cell. Biol. 2001, 3, 158-164.

44. Lin, J.H.; Li, H.; Yasumura, D.; Cohen, H.R.; Zhang, C.; Panning, B.; Shokat, K.M.; Lavail, M.M.; Walter, P. IRE1 signaling affects cell fate during the unfolded protein response. Science 2007, 318, 944-949.

45. Lin, J.H.; Li, H.; Zhang, Y.; Ron, D.; Walter, P. Divergent effects of PERK and IRE1 signaling on cell viability. PLoS One 2009, 4, e4170.

46. Tsvetanova, N.G.; Riordan, D.P.; Brown, P.O. The Yeast Rab GTPase Ypt1 Modulates Unfolded Protein Response Dynamics by Regulating the Stability of HAC1 RNA. PLoS Gen. 2012, 8, e1002862.

47. Chapman, R.E.; Walter, P. Translational attenuation mediated by an mRNA intron. Curr. Biol. 1997, 7, 850-859.

48. Kawahara, T.; Yanagi, H.; Yura, T.; Mori, K. Endoplasmic reticulum stress-induced mRNA splicing permits synthesis of transcription factor Hac1p/Ern $4 p$ that activates the unfolded protein response. Mol. Biol. Cell. 1997, 8, 1845-1862.

49. Pincus, D.; Chevalier, M.W.; Aragon, T.; van Anken, E.; Vidal, S.E.; El-Samad, H.; Walter, P. BiP binding to the ER-stress sensor Ire1 tunes the homeostatic behavior of the unfolded protein response. PLoS Biol. 2010, 8, e1000415.

50. Ruegsegger, U.; Leber, J.H.; Walter, P. Block of HAC1 mRNA translation by long-range base pairing is released by cytoplasmic splicing upon induction of the unfolded protein response. Cell 2001, 107, 103-114.

51. Kim, I.; Xu, W.; Reed, J.C. Cell death and endoplasmic reticulum stress: Disease relevance and therapeutic opportunities. Nat. Rev. Drug Dis. 2008, 7, 1013-1030. 
52. Shamu, C.E.; Walter, P. Oligomerization and phosphorylation of the Ire1p kinase during intracellular signaling from the endoplasmic reticulum to the nucleus. EMBO J. 1996, 15, 3028-3039.

53. Lai, C.W.; Aronson, D.E.; Snapp, E.L. BiP availability distinguishes states of homeostasis and stress in the endoplasmic reticulum of living cells. Mol. Biol. Cell. 2010, 21, 1909-19021.

54. Li, H.; Korennykh, A.V.; Behrman, S.L.; Walter, P. Mammalian endoplasmic reticulum stress sensor IRE1 signals by dynamic clustering. Proc. Natl. Acad. Sci. USA 2010, 107, 16113-16118.

55. Korennykh, A.V.; Egea, P.F.; Korostelev, A.A.; Finer-Moore, J.; Stroud, R.M.; Zhang, C.; Shokat, K.M.; Walter, P. Cofactor-mediated conformational control in the bifunctional kinase/RNase Ire1. BMC Biol. 2011, 9, 48.

56. Lee, K.P.; Dey, M.; Neculai, D.; Cao, C.; Dever, T.E.; Sicheri, F. Structure of the dual enzyme Ire1 reveals the basis for catalysis and regulation in nonconventional RNA splicing. Cell 2008, 132, 89-100.

57. Liu, C.Y.; Wong, H.N.; Schauerte, J.A.; Kaufman, R.J. The protein kinase/endoribonuclease IRE1alpha that signals the unfolded protein response has a luminal N-terminal ligand-independent dimerization domain. J. Biol. Chem. 2002, 277, 18346-18356.

58. Aragon, T.; van Anken, E.; Pincus, D.; Serafimova, I.M.; Korennykh, A.V.; Rubio, C.A.; Walter, P. Messenger RNA targeting to endoplasmic reticulum stress signalling sites. Nature 2009, 457, 736-740.

59. Promlek, T.; Ishiwata-Kimata, Y.; Shido, M.; Sakuramoto, M.; Kohno, K.; Kimata, Y. Membrane aberrancy and unfolded proteins activate the endoplasmic reticulum stress sensor Ire1 in different ways. Mol. Biol. Cell. 2011, 22, 3520-3532.

60. Zhou, J.; Liu, C.Y.; Back, S.H.; Clark, R.L.; Peisach, D.; Xu, Z.; Kaufman, R.J. The crystal structure of human IRE1 luminal domain reveals a conserved dimerization interface required for activation of the unfolded protein response. Proc. Natl. Acad. Sci. USA 2006, 103, 14343-14348.

61. Ali, M.M.; Bagratuni, T.; Davenport, E.L.; Nowak, P.R.; Silva-Santisteban, M.C.; Hardcastle, A.; McAndrews, C.; Rowlands, M.G.; Morgan, G.J.; Aherne, W.; et al. Structure of the Ire1 autophosphorylation complex and implications for the unfolded protein response. EMBO J. 2011, 30, 894-905.

62. Korennykh, A.V.; Egea, P.F.; Korostelev, A.A.; Finer-Moore, J.; Zhang, C.; Shokat, K.M.; Stroud, R.M.; Walter, P. The unfolded protein response signals through high-order assembly of Ire1. Nature 2009, 457, 687-693.

63. Wiseman, R.L.; Zhang, Y.; Lee, K.P.; Harding, H.P.; Haynes, C.M.; Price, J.; Sicheri, F.; Ron, D. Flavonol activation defines an unanticipated ligand-binding site in the kinase-RNase domain of IRE1. Mol. Cell. 2010, 38, 291-304.

64. Thibault, G.; Ismail, N.; Ng, D.T. The unfolded protein response supports cellular robustness as a broad-spectrum compensatory pathway. Proc. Natl. Acad. Sci. USA 2011, 108, 20597-20602.

65. Onn, A.; Ron, D. Modeling the endoplasmic reticulum unfolded protein response. Nat. Struct. Mol. Biol. 2010, 17, 924-925.

66. Oikawa, D.; Kimata, Y.; Kohno, K. Self-association and BiP dissociation are not sufficient for activation of the ER stress sensor Ire1. J. Cell. Sci. 2007, 120, 1681-1688. 
67. Normington, K.; Kohno, K.; Kozutsumi, Y.; Gething, M.J.; Sambrook, J.S. cerevisiae encodes an essential protein homologous in sequence and function to mammalian BiP. Cell 1989, 57, 1223-1236.

68. Liu, C.Y.; Xu, Z.; Kaufman, R.J. Structure and intermolecular interactions of the luminal dimerization domain of human IRE1alpha. J. Biol. Chem. 2003, 278, 17680-17687.

69. Gething, M.J. Role and regulation of the ER chaperone BiP. Semin. Cell. Dev. Biol. 1999, 10, $465-472$.

70. Dudek, J.; Benedix, J.; Cappel, S.; Greiner, M.; Jalal, C.; Muller, L.; Zimmermann, R. Functions and pathologies of BiP and its interaction partners. Cell. Mol. Life Sci. 2009, 66, 1556-1569.

71. Hendershot, L.M. The ER function BiP is a master regulator of ER function. Mt. Sinai. J. Med. 2004, 71, 289-297.

72. Otero, J.H.; Lizak, B.; Hendershot, L.M. Life and death of a BiP substrate. Semin. Cell. Dev. Biol. 2010, 21, 472-478.

73. Kohno, K.; Normington, K.; Sambrook, J.; Gething, M.J.; Mori, K. The promoter region of the yeast KAR2 (BiP) gene contains a regulatory domain that responds to the presence of unfolded proteins in the endoplasmic reticulum. Mol. Cell. Biol. 1993, 13, 877-890.

74. Schuldiner, M.; Collins, S.R.; Thompson, N.J.; Denic, V.; Bhamidipati, A.; Punna, T.; Ihmels, J.; Andrews, B.; Boone, C.; Greenblatt, J.F.; et al. Exploration of the function and organization of the yeast early secretory pathway through an epistatic miniarray profile. Cell 2005, 123, 507-519.

75. Okamura, K.; Kimata, Y.; Higashio, H.; Tsuru, A.; Kohno, K. Dissociation of Kar2p/BiP from an ER sensory molecule, Irelp, triggers the unfolded protein response in yeast. Biochem. Biophys. Res. Commun. 2000, 279, 445-450.

76. Mintz, M.; Vanderver, A.; Brown, K.J.; Lin, J.; Wang, Z.; Kaneski, C.; Schiffmann, R.; Nagaraju, K.; Hoffman, E.P.; Hathout, Y. Time series proteome profiling to study endoplasmic reticulum stress response. J. Proteom. Res. 2008, 7, 2435-2444.

77. Wiest, D.L.; Burkhardt, J.K.; Hester, S.; Hortsch, M.; Meyer, D.I.; Argon, Y. Membrane biogenesis during $\mathrm{B}$ cell differentiation: Most endoplasmic reticulum proteins are expressed coordinately. J. Cell. Biol. 1990, 110, 1501-1511.

78. Hsu, C.L.; Prasad, R.; Blackman, C.; Ng, D.T. ER stress regulation of the Kar2p/BiP chaperone alleviates proteotoxicity via dual degradation pathways. Mol. Biol. Cell. 2012, 23, 630-641.

79. Kimata, Y.; Kimata, Y.I.; Shimizu, Y.; Abe, H.; Farcasanu, I.C.; Takeuchi, M.; Rose, M.D.; Kohno, K. Genetic evidence for a role of $\mathrm{BiP} / \mathrm{Kar} 2$ that regulates Ire1 in response to accumulation of unfolded proteins. Mol. Biol. Cell. 2003, 14, 2559-2569.

80. Liu, C.Y.; Schroder, M.; Kaufman, R.J. Ligand-independent dimerization activates the stress response kinases IRE1 and PERK in the lumen of the endoplasmic reticulum. J. Biol. Chem. 2000, 275, 24881-24885.

81. Morris, J.A.; Dorner, A.J.; Edwards, C.A.; Hendershot, L.M.; Kaufman, R.J. Immunoglobulin binding protein $(\mathrm{BiP})$ function is required to protect cells from endoplasmic reticulum stress but is not required for the secretion of selective proteins. J. Biol. Chem. 1997, 272, 4327-4334.

82. Guth, S.; Volzing, C.; Muller, A.; Jung, M.; Zimmermann, R. Protein transport into canine pancreatic microsomes: a quantitative approach. Eur. J. Biochem. 2004, 271, 3200-3207. 
83. Schwanhausser, B.; Busse, D.; Li, N.; Dittmar, G.; Schuchhardt, J.; Wolf, J.; Chen, W.; Selbach, M. Global quantification of mammalian gene expression control. Nature 2011, 473, 337-342.

84. Ghaemmaghami, S.; Huh, W.K.; Bower, K.; Howson, R.W.; Belle, A.; Dephoure, N.; O'Shea, E.K.; Weissman, J.S. Global analysis of protein expression in yeast. Nature 2003, 425, 737-741.

85. Lai, C.W.; Otero, J.H.; Hendershot, L.M.; Snapp, E. ERdj4 protein is a soluble endoplasmic reticulum (ER) DnaJ family protein that interacts with ER-associated degradation machinery. J. Biol. Chem. 2012, 287, 7969-7978.

86. Oikawa, D.; Kimata, Y.; Kohno, K.; Iwawaki, T. Activation of mammalian IRE1alpha upon ER stress depends on dissociation of BiP rather than on direct interaction with unfolded proteins. Exp. Cell. Res. 2009, 315, 2496-2504.

87. Marcinowski, M.; Holler, M.; Feige, M.J.; Baerend, D.; Lamb, D.C.; Buchner, J. Substrate discrimination of the chaperone BiP by autonomous and cochaperone-regulated conformational transitions. Nat. Struct. Mol. Biol. 2011, 18, 150-158.

88. Vanhove, M.; Usherwood, Y.K.; Hendershot, L.M. Unassembled Ig heavy chains do not cycle from BiP in vivo but require light chains to trigger their release. Immunity 2001, 15, 105-114.

89. Lajoie, P.; Moir, R.D.; Willis, I.M.; Snapp, E.L. Kar2p Availability Defines Distinct Forms of Endoplasmic Reticulum Stress in Living Cells. Mol. Biol. Cell. 2012, doi: 10.1091/mbc.E11-120995.

90. Kang, S.W.; Rane, N.S.; Kim, S.J.; Garrison, J.L.; Taunton, J.; Hegde, R.S. Substrate-specific translocational attenuation during ER stress defines a pre-emptive quality control pathway. Cell 2006, 127, 999-1013.

91. Marciniak, S.J.; Yun, C.Y.; Oyadomari, S.; Novoa, I.; Zhang, Y.; Jungreis, R.; Nagata, K.; Harding, H.P.; Ron, D. CHOP induces death by promoting protein synthesis and oxidation in the stressed endoplasmic reticulum. Genes Dev. 2004, 18, 3066-3077.

92. Kuznetsov, G.; Chen, L.B.; Nigam, S.K. Multiple molecular chaperones complex with misfolded large oligomeric glycoproteins in the endoplasmic reticulum. J. Biol. Chem. 1997, 272, 3057-3063.

93. Chambers, J.E.; Petrova, K.; Tomba, G.; Vendruscolo, M.; Ron, D. ADP ribosylation adapts an ER chaperone response to short-term fluctuations in unfolded protein load. J. Cell. Biol. 2012, 198, 371-385.

94. Freiden, P.J.; Gaut, J.R.; Hendershot, L.M. Interconversion of three differentially modified and assembled forms of BiP. EMBO J. 1992, 11, 63-70.

95. Leno, G.H.; Ledford, B.E. ADP-ribosylation of the $78-\mathrm{kDa}$ glucose-regulated protein during nutritional stress. FEBS J. 1989, 186, 205-211.

96. Hendershot, L.M.; Ting, J.; Lee, A.S. Identity of the immunoglobulin heavy-chain-binding protein with the 78,000-dalton glucose-regulated protein and the role of posttranslational modifications in its binding function. Mol. Cell. Biol. 1988, 8, 4250-4256.

97. Laitusis, A.L.; Brostrom, M.A.; Brostrom, C.O. The dynamic role of GRP78/BiP in the coordination of mRNA translation with protein processing. J. Biol. Chem. 1999, 274, 486-493.

98. Carlsson, L.; Lazarides, E. ADP-ribosylation of the $\mathrm{Mr} 83,000$ stress-inducible and glucoseregulated protein in avian and mammalian cells: modulation by heat shock and glucose starvation. Proc. Natl. Acad. Sci. USA 1983, 80, 4664-4668. 
99. Griffiths, G.; Warren, G.; Quinn, P.; Mathieu-Costello, O.; Hoppeler, H. Density of newly synthesized plasma membrane proteins in intracellular membranes. I. Stereological studies. J. Cell. Biol. 1984, 98, 2133-2141.

100. Todd-Corlett, A.; Jones, E.; Seghers, C.; Gething, M.J. Lobe IB of the ATPase domain of $\mathrm{Kar} 2 \mathrm{p} / \mathrm{BiP}$ interacts with Ire1p to negatively regulate the unfolded protein response in Saccharomyces cerevisiae. J. Mol. Biol. 2007, 3, 67,770-787.

101. Cox, J.S.; Chapman, R.E.; Walter, P. The unfolded protein response coordinates the production of endoplasmic reticulum membrane. Mol. Biol. Cell. 1997, 8, 1805-1814.

102. Nikawa, J.; Akiyoshi, M.; Hirata, S.; Fukuda, T. Saccharomyces cerevisiae IRE2/HAC1 is involved in IRE1-mediated KAR2 expression. Nucleic. Acids Res. 1996, 24, 4222-4226.

103. Mori, K.; Ogawa, N.; Kawahara, T.; Yanagi, H.; Yura, T. mRNA splicing-mediated C-terminal replacement of transcription factor Hac1p is required for efficient activation of the unfolded protein response. Proc. Natl. Acad. Sci. USA 2000, 97, 4660-4665.

104. Travers, K.J.; Patil, C.K.; Wodicka, L.; Lockhart, D.J.; Weissman, J.S.; Walter, P. Functional and genomic analyses reveal an essential coordination between the unfolded protein response and ER-associated degradation. Cell 2000, 101, 249-258.

105. Brickner, J.H.; Walter, P. Gene recruitment of the activated INO1 locus to the nuclear membrane. PLoS Biol. 2004, 2, e342.

106. Contreras, F.X.; Ernst, A.M.; Haberkant, P.; Bjorkholm, P.; Lindahl, E.; Gonen, B.; Tischer, C.; Elofsson, A.; von Heijne, G.; Thiele, C.; et al. Molecular recognition of a single sphingolipid species by a protein's transmembrane domain. Nature 2012, 481, 525-529.

107. Hetz, C.; Glimcher, L.H. Fine-tuning of the unfolded protein response: Assembling the IRE1alpha interactome. Mol. Cell. 2009, 35, 551-561.

108. Hetz, C.; Martinon, F.; Rodriguez, D.; Glimcher, L.H. The unfolded protein response: Integrating stress signals through the stress sensor IRE1alpha. Physiol Rev. 2011, 91, 1219-1243.

109. Lisbona, F.; Rojas-Rivera, D.; Thielen, P.; Zamorano, S.; Todd, D.; Martinon, F.; Glavic, A.; Kress, C.; Lin, J.H.; Walter, P.; et al. BAX inhibitor-1 is a negative regulator of the ER stress sensor IRE1alpha. Mol. Cell. 2009, 33, 679-691.

110. Marcu, M.G.; Doyle, M.; Bertolotti, A.; Ron, D.; Hendershot, L.; Neckers, L. Heat shock protein 90 modulates the unfolded protein response by stabilizing IRE1alpha. Mol. Cell. Biol. 2002, 22, 8506-8513.

111. Lamb, H.K.; Mee, C.; Xu, W.; Liu, L.; Blond, S.; Cooper, A.; Charles, I.G.; Hawkins, A.R. The affinity of a major $\mathrm{Ca}^{2+}$ binding site on GRP78 is differentially enhanced by ADP and ATP. J. Biol. Chem. 2006, 281, 8796-8805.

112. Guo, J.; Polymenis, M. Dcr2 targets Ire1 and downregulates the unfolded protein response in Saccharomyces cerevisiae. EMBO Rep. 2006, 7, 1124-1127.

113. Welihinda, A.A.; Tirasophon, W.; Green, S.R.; Kaufman, R.J. Protein serine/threonine phosphatase Ptc2p negatively regulates the unfolded-protein response by dephosphorylating Ire1p kinase. Mol. Cell. Biol. 1998, 18, 1967-1977.

114. Frost, A.; Elgort, M.G.; Brandman, O.; Ives, C.; Collins, S.R.; Miller-Vedam, L.; Weibezahn, J.; Hein, M.Y.; Poser, I.; Mann, M.; et al. Functional repurposing revealed by comparing S. pombe and S. cerevisiae genetic interactions. Cell 2012, 149, 1339-1352. 
115. Liu, Y.; Chang, A. Heat shock response relieves ER stress. EMBO J. 2008, 27, 1049-1059.

116. DuRose, J.B.; Tam, A.B.; Niwa, M. Intrinsic capacities of molecular sensors of the unfolded protein response to sense alternate forms of endoplasmic reticulum stress. Mol. Biol. Cell. 2006, 17, 3095-3107.

117. Maiuolo, J.; Bulotta, S.; Verderio, C.; Benfante, R.; Borgese, N. Selective activation of the transcription factor ATF6 mediates endoplasmic reticulum proliferation triggered by a membrane protein. Proc. Natl. Acad. Sci. USA. 2011, 108, 7832-7837.

(C) 2012 by the author; licensee MDPI, Basel, Switzerland. This article is an open-access article distributed under the terms and conditions of the Creative Commons Attribution license (http://creativecommons.org/licenses/by/3.0/). 